\title{
On College English Vocabulary Teaching Strategies from the Perspective of Constructivism
}

\author{
Jia Yu \\ School of Foreign Languages, Southwest Petroleum University, Chengdu, Sichuan, China
}

\begin{abstract}
The application of constructivism theory in vocabulary teaching makes it possible to put forward some college English vocabulary teaching strategies, including the root-affix lexical bundle construction, the sound-morpheme-meaning construction, the word-context-dynamic semantic construction, the experience-cognitive activation-schematic construction, which is conducive to the combination of top-down explanation by teachers and bottom-up construction by students, giving full play to students' subjective initiative in vocabulary learning and improving teachers' vocabulary teaching efficiency.
\end{abstract}

Keywords: Constructivism, Vocabulary teaching, CET-4, Lexical bundle.

\section{Introduction}

Vocabulary, as a medium, is of strategic significance in semantic expression. As Wilkins presented "Without grammar very little can be conveyed, without vocabulary nothing can be conveyed"'[1]. The vocabulary proficiency of the target language greatly affects the language use of learners. Therefore, teachers are required to adopt appropriate strategies in vocabulary teaching, helping and promoting learners to internalize knowledge that they have learnt.

The actuality of college English vocabulary teaching and learning, however, is not optimistic. In terms of vocabulary teaching, due to the influence of Grammar-Translation Method, the teaching emphasis is more on syntactic structure and text comprehension, while vocabulary is in a marginal position; In addition, Teachers tend to preach, while language learning strategies are rarely involved, giving rise to the lack of independent inquiry process for students; What's more, the three-step teaching method of reading-spelling-meaning is more likely to be adopted by teachers, ignoring word formation, semantic variation and cultural connotation of words in context. The combination of the above problems and the passivity of students' vocabulary learning leads to the students memorizing vocabularies mechanically, only mastering the literal meaning of the words, and making mistakes in practical application, which are manifested as poor memory of sound, spell and meaning, improper construction of semantic field, inappropriate words collocation.

Therefore, it has the vital practical significance to explore how to conduct effective college English vocabulary teaching.

\section{Constructivism}

\subsection{Origins and Development of Constructivism}

The birth of constructivism theory is greatly influenced by philosophy and psychology.

Nola, a New Zealand scholar, believed that Socrates and Plato are the earliest constructivists in the field of education, because they both opposed the direct teaching of knowledge to students, among which Socrates' midwifery is regarded as a successful prototype of constructivism teaching[2]. In modern times, the famous Italian philosopher Vico was respected as the pioneer of constructivism, and the famous German philosopher Kant was considered to be closely related to constructivism as well.

After 1950s, the absolute position of rationalism was broken, and cognitivism gradually developed into constructivism. Piaget, a famous Swiss psychologist, was regarded as the earliest proposer of contemporary constructivism on account of his theory of children's cognitive development. Henceforward, Kohlberg made further studies on the nature and development conditions of cognitive structure, Sternberg and Katz explored how to give play to individual initiative in the cognitive process, and Vygotsky's cultural-historical development theory laid a foundation for the formation of contemporary constructivism theory[3].

\subsection{Basic Concepts of Constructivism}

According to Piaget's theory of children's cognitive development, children gradually construct knowledge about the outside world in the process of interacting with the surrounding environment, so as to develop their own cognitive structure. The interaction between children and the environment involves two basic processes: assimilation and adaptation. The former refers to the integration of the new information provided by the external environment stimulus into the existing knowledge structure, while the latter refers to the process of restructuring or transforming the original cognitive structure to adapt to the fresh environment and new information[4]. Constructivism learning theory comes into being on this basis.

Constructivism learning theory holds that learning is a process of active construction. Under a certain social and cultural background, learners actively and selectively perceive external information according to the existing cognitive structure, and construct the meaning of current things with the help of others, such as teachers and learning partners by using necessary learning materials[5]. Teachers only play a guiding and promoting role in the process of learners' meaning construction, which requires teachers to create scenes actively, promote cooperation and organize 
conversations in the teaching process to help students achieve meaning construction.

Constructivism is a revolution of contemporary learning theory, which influences the development trend of instructional design theory and practice[6][7], playing an important role in college English vocabulary teaching.

\section{Literature Review}

The novel teaching ideas advocated by constructivism theory just hit the defect of Chinese traditional teaching modes, as a consequence, Chinese scholars got down to conduct researches on the theory and practice of constructivism systematicly and thoroughly. He Kekang discussed in detail the origin and development of constructivism theory, including its learning theory, learning methods and teaching models etc[8]. Gaowen traced the ideological origin of constructivism on the theoretical basis of philosophy and psychology[9]. Chen Qi elaborated the development, basic viewpoints and the process of learning cognitive construction of constructivism from the perspectives of pedagogy and psychology[10].

With the help of the above researches, more and more scholars combined the constructivism theory with English language teaching, exploring English teaching models, writing, reading and translation teaching, etc. There were some scholars applying constructivism theory to vocabulary teaching, for instance, Zhang Ming studied vocabulary learning strategies and teaching models for English majors[11]. Huang Leping and Wang Junchao discussed the motivation and constructions of vocabulary teaching in detail[12]. Zhu Min made a review of Applied English Lexicology, emphasizing the importance of helping students build up their mental lexicon and teaching vocabulary comprehensively[13]. Miao Zhuang conducted an empirical study on English vocabulary teaching in a senior high school by flipped class model under the guidance of constructivism[14].

Previous studies explored English vocabulary teaching models from a theoretical perspective, lacking qualitative analysis. Therefore, this paper combines constructivism theory with vocabulary teaching examples in order to put forward some new strategies to provide effective reference for college English vocabulary teaching.

\section{English Vocabulary Teaching Strategies under the Guidance of Constructivism}

Candidates are required to master 4200 vocabulary by the CET-4 syllabus and have the ability to identify new words according to the basic word-formation method. For the sake of realizing the teaching requirement, teachers need to pay attention to the motivation of vocabularies and their variations in context. The following strategies can be used to help students complete meaning construction in vocabulary teaching.

\subsection{Strategy 1: Root-affix Lexical Bundle Construction}

English word formation can be divided into derivation, compounding and conversion, among which derivation is the most productive[12]. Derivative words are composed of affixes or roots. Affixes are composed of prefixes and suffixes. The former changes the meaning of words, such as negative prefixes in-, im-, un-, non-, de-, time prefixes pre-, fore-, ex-, post-, while the latter alters the part of speech, such as noun suffixes -er, -ment, -ion, -ship, -hood, -ness, -ty, -al, verb suffixes -ify, -en, -ate. Root is the core part of a word, determining its basic meaning, for instance, acid referring to sour, audi signifying hear, seism representing earthquake.

In the teaching of affixes, the top-down approach can be adopted to explain the meaning of affixes and help students to grasp the motivation of vocabulary and enlarge their vocabulary size, while in the teaching of roots, teachers can ask students to summarize and classify the words they have learned, discuss with other learners, discover and summarize the rules of word roots, and finally achieve the purpose of drawing inferences from one another. Here are some examples:

\section{(1) October}

Students are familiar with the word October, but they know less about the prefix octo-. When teaching, teachers can make use of students' original knowledge, explaining the original meaning of the prefix octo- is eight, such as "octopus", so that students can explore the reason why October is translated into the tenth month of a year by communicating with students or searching information on the Internet.

The Gregorian calendar commonly used in the world today originated from the ancient Roman calendar, which originally lasted only ten months. January and February were added to the beginning of a year after the calendar reform, so October moved backwards to become the tenth month. In the same way, we can see that the prefix dec- originally refers to ten, as in "decade", "decimal", but December is translated as the twelfth month of a year. Students' learning interests can be stimulated by vocabulary stories, so that they are more likely to take the initiative to construct meanings. In addition, with the help of teacher-student cooperation and students' communication, the memory of words can be strengthened. Students will form the following lexical bundles through vocabulary extension and construction:

$\sum($-octo $)=\{$ October - octopus \& December — decade decimal...

\section{(2) contain}

Based on the knowledge already learned, students can identify the prefix con- as emphasis, such as "connect", "contact". Bottom-up teaching method can be adopted by teachers, asking the students to list the words with the root -tain, and then organizing the students to cooperate and discuss the meaning of the root -tain. The steps are shown in Table 1: 
Table 1: Lexical bundles construction of -tain

\begin{tabular}{|c|c|c|c|c|c|}
\hline \multirow{2}{*}{ Step1 } & \multirow{2}{*}{ Decomposition } & Prefix & Root & Word & $\begin{array}{c}\text { Basic } \\
\text { meaning }\end{array}$ \\
\hline & & con- & \multirow{6}{*}{-tain } & contain & $\begin{array}{c}\text { have as a } \\
\text { component }\end{array}$ \\
\hline \multirow{5}{*}{ Step2 } & \multirow{5}{*}{ Enumeration } & at- $(=\mathrm{ad})$ & & attain & $\begin{array}{l}\text { to gain with } \\
\text { effort }\end{array}$ \\
\hline & & ob- & & obtain & to get sth \\
\hline & & sus- & & sustain & $\begin{array}{c}\text { to make sth } \\
\text { continue }\end{array}$ \\
\hline & & $\begin{array}{c}\text { main- } \\
(=\text { manu })\end{array}$ & & maintain & $\begin{array}{c}\text { keep in a } \\
\text { certain state }\end{array}$ \\
\hline & & re- & & retain & to keep sth \\
\hline Step3 & $\begin{array}{c}\text { Rules } \\
\text { Summary }\end{array}$ & The $r$ & ain & ins to "hol & or "have" \\
\hline
\end{tabular}

Students can assimilate new knowledge into the original cognitive system in this way, and the lexical bundles formed by students now is:

$$
\begin{aligned}
& \sum(\text {-tain })=\{\text { contain }- \text { attain }- \text { obtain }- \text { sustain }- \text { maintain } \\
& \text { retain... }\}
\end{aligned}
$$

\subsection{Strategy 2: Sound-morpheme-meaning Construction}

Sound-morpheme-meaning, as a common method in English vocabulary teaching, refers to the construction and memory of vocabularies by guiding students to pronounce, recognize form and construct meaning[15], which includes pronunciation association mnemonic method and morpheme extension mnemonic method. The former helps students remember words according to the rhythm or consonant, and the latter builds morpheme frame according to the words shape to enlarge vocabularies, for example:

\section{(3) Giggle}

There are myriad of onomatopoeia in English, which provide motivation for the generation of words, whether describing the sounds of natural things or human sounds. Therefore, the pronunciation association mnemonic method is helpful for teachers to improve the efficiency of vocabulary teaching.

The word giggle means "to laugh in a silly way because you are amused, embarrassed or nervous", showing a strong connection between the sound and its word formation. Teachers can request students to imitate pronunciation and make full use of their cognition of the world to remember words by associating words with scenes, such as the following occasions:

The girls giggled at the joke.

They giggled nervously as they waited for their turn.

In addition, other onomatopoeia related to laughter can be added to vocabulary teaching for semantic discrimination, such as chuckle, titter and gurgle, so that the lexical bundles can be generalized by the students:

\{ giggle - chuckle - titter — gurgle - chortle — snort roar - burble...

\section{(4) Worm}

Morpheme extension mnemonic method refers to the induction of the potential motivation according to the external structure of a word, followed by the construction of lexical bundles. The word "worm" is like "a long thin creature with no bones or legs, that lives in soil or inside the bodies of humans or animals" from the morphological point of view, which can be extended to wring, wriggle and squirm. The lexical bundles can be formed by analogy:

\{worm - wring - wriggle - squirm... $\}$

Obviously, in order to encourage students to expand vocabulary actively and consciously, teachers are required to take the initiative to guide students to construct lexical bundles.

\subsection{Strategy 3: Word-context-dynamic Semantic Construction}

The discussion on static meaning and teaching methods of vocabulary is followed by the dynamic meaning of vocabulary and the corresponding teaching strategies, which are more worthy of study. As Malinowski said, without context, words are mere fragments and have no meaning[16]. Context refers to "the words that come just before and after a word, phrase or statement and help you to understand its meaning" in Oxford Advanced Learner's Dictionary, consisting of situational context and linguistic context[16]. Due to the semantic variation of vocabulary often occurs with the specific context, teachers are supposed to serve guidance to students, helping them construct the dynamic meaning of vocabulary by speculating meanings according to co-text, juxtaposed examples, appositive or attributive clause, etc.

(5) The old man put on his spectacles and began to read.

Although the word "spectacle" is a new word, it is effortless for students to construct the meaning of it in the context. "Spectacle" is an object used for reading and needed to be worn, so that the word means "glasses" apparently, which echoes "the old man".

(6) Today young couples who are just starting their households often spend lots of their money on appliances for instance, washing machines, refrigerators and color televisions.

In this sentence, "appliance" is relatively unfamiliar for students, but they can infer that appliance is a hypernym based on the enumeration following "for instance". On the basis of the common attribute of the words "washing machines", "refrigerators" and "color televisions", the word "appliance" refers to a device or machine designed to do a particular thing in the home, which is often electrical.

(7) The invention of snorkel, a long air tube that reaches up to the surface, has made it possible for submarine to use their diesel engine even when they are submerged.

The word "snorkel" is the core word of the sentence and fresh one. The appositive "a long air tube that reaches up to the surface" after it describes its characteristics vividly. Combining this definition with the context, students can deduce what it means to be a tube through which a person swimming just under the surface of the sea can breathe. 


\subsection{Strategy 4: Experience-cognitive activation-schematic Construction}

Schema is the existing knowledge and experience network in the human brain, which is the cognitive structure representing a specific concept, object or event[17]. In other words, schema theory holds that individuals process new information related to themselves according to their existing self-schemas and form a general understanding of themselves based on their previous experience, which is of great guiding significance to English vocabulary teaching. In the teaching of new words, teachers ought to assist students to construct schemata and simulate scenes according to their original knowledge, so as to learn a series of words related to the scenes.

(8) Paper cutting is a unique form of Chinese traditional folk art with a history of more than 2,000 years. The materials and tools for paper cutting are simple: paper and scissors. Paper cutting works are usually made of red paper, because red is associated with happiness in traditional Chinese culture. Therefore, in the wedding, the Spring Festival and other festive occasions, red paper cutting is the first choice of door and window decoration (CET-4 translation in June 2019, Vol.1).

The above paragraph describes the folk art of paper cutting. When teaching, teachers are able to use multimedia to show the pictures or videos of paper cutting to students, and even carry out a paper cutting activity to activate students' cognition of it. In this way, the corresponding encephalic area will be activated by students, which can be stimulated as well when describing the paper cutting activity in words. During repeated activation, students will construct schemas and form the following lexical bundles based on their original cognition:

$\sum$ (Paper cutting $)=\{$ Nature $($ Chinese traditional folk art $)-$ Materials and tools (red paper and scissors) - Symbol (happiness) - Application (wedding/the Sping Festival) Function (door/window decoration)...

By analogy, paper-cutting activities can be extended to other folk arts by teachers, for example:

(9) Lion dance, as a traditional folk performance in China, has a history of over 2,000 years. During the dance, there are two performers wearing a lion costume, with one controlling the head and the other controlling the body and the tail. They cooperate with each other skillfully and imitate various movements of a lion. Lion, as the King of the Beasts, symbolizes happiness and good fortune. Therefore, lion dance is often performed during the Spring Festival and other festivals. It may also appear in other important occasions like business openings and wedding ceremonies, which attracts many people to watch (CET-4 translation in June 2019, Vol.3).

Most students are likely to have seen the lion dance live or online, so there are lion dance-related vocabularies in their cognition. In this case, the embodiment-activation- schematic construction model is very beneficial to the construction of students' vocabulary framework. Role-playing, showing pictures or videos can help students learn vocabulary on the basis of experience and cognition. During the experience and subsequent reading of the text, students are capable of finding and filling in new slots, thus constructing a more complex and experiential "lion dance" situation and storing it in memory as a knowledge node. Compared with traditional word teaching, this strategy is characterized by the experiencability, constructability and systematization of vocabulary.

$\sum($ Lion dance $)=\{$ Nature $\quad$ (Chinese traditional folk performance) - Performance (wear a lion costume/control the lion/cooperate/imitate) — Symbol (happiness \& good fortune) - Application (the Sping Festival/business openings/wedding ceremonies) — Function (attract attention)...

Teachers and students can further construct a more complete and fluent schema to strengthen students' memory of new words in subsequent learning.

\section{Conclusion}

In college English vocabulary teaching, it should be noted that teachers are supposed to adopt a variety of strategies consciously to create an advantageous environment for students. While teaching, students should be encouraged to use their existing cognitions to actively construct meaning in collaboration with teachers and other learners, assimilating new knowledge into the original cognitive system or reconstructing new ones. The teaching task of teachers is to make students not only understand the literal meaning of words, but also understand the motivation and their dynamic variations in context by adopting different teaching strategies, diversifing teaching forms, to stimulate students' interest in vocubulary learning, promoting the comprehensive development of students.

\section{References}

[1] Wilkins, D. A, Linguistics in Language Teaching, MA: MIT Press, Cambridge, 1972.

[2] Zuo Yinfang editor-in-chief, Educational Psychology, Huazhong University of Science and Technology Press, Wuhan, 2015.

[3] MBA, "Constructivism Learning Theory," para. 2\&3, Mar. 1, 2016. [Online]. Available: https://wiki.mbalib.com/wiki/Constructivism Theory. [Accessed: Dec. 18, 2021].

[4] Piaget, J, The Psychology of the Child, Basic Books, New York, 1972.

[5] Zhou Rongsheng, "English Teaching Model Based on Constructivism Theory," Education Review, (8), PP. 147-149, 2018.

[6] Zhong Zhixian, "Constructivist Learning Theories and Instructional Design," E-education Research, (5), PP. 10-16, 2006.

[7] Zhu Tianyi, "English Vocabulary Teaching in Junior Middle School from the Perspective of Constructivism Learning Theory," Overseas English, (2), PP. 14-16, 2018.

[8] He Kekang, "Constructivism: The Theoretical Basis of Reforming Traditional Teaching," E-education Research, XVIII (3), PP. 3-9, 1997. 
[9] Gao Wen, Xu Binyan, Wu Gang, Constructivism in Education, Educational Science Publishing House, Bei Jing, 2008.

[10] Chen Qi, Liu Rude, Educational Psychology, Higher Education Press, Beijing, 2011.

[11] Zhang Min, "Vocabulary Learning for English Majors from the Perspective of Constructivism Theory," Education and Vocation, (11), PP. 107-108, 2012.

[12] Huang Leping, Wang Junchao, "A Constructivism Approach to Teaching and Learning Vocabulary: Exploring the Motivations and Constructions," Foreign Language Research, (5), PP. 112-117, 2015.

[13] Zhu Min, "On English Vocabulary Teaching under Constructivism: A Review of Applied English Lexicology," News and Writing, (1), PP. 126, 2018.

[14] Miao Zhuang, "On the Flipped Classroom Teaching of English Vocabulary in Senior High School from the Perspective of Constructivism Theory," English Teaching \& Research Notes, (6), PP. 25-29, 76, 2019.

[15] Wang Yuying, Li Hexin, "The Relationship Between Word's Pronunciation, Form and Meaning on the One hand and the Learning and Memorizing of the Word on the Other," Journal of Shanxi University (Philosophy \& Social Sciences), XXIV(6), PP.86-87, 2001.

[16] Verschueren, J, Understanding Pragmatics, Oxford University Press, London, 1999.

[17] Hui Ying, "The Discuss of Schema Concept of Kant, Piaget and Present Cognitive Psychology," Science of Social Psychology, (9), PP. 21-24, 28, 2010.

\section{Author Profile}

Jia Yu received the B.S. degree in English from Southwest Petroleum University in 2015. She is now continuing M.S. degree in Foreign Linguistics and Applied Linguistics in SWPU. 